\title{
FIBROMYALGIA SYNDROME
}

\author{
Michael Doherty, Adrian Jones
}

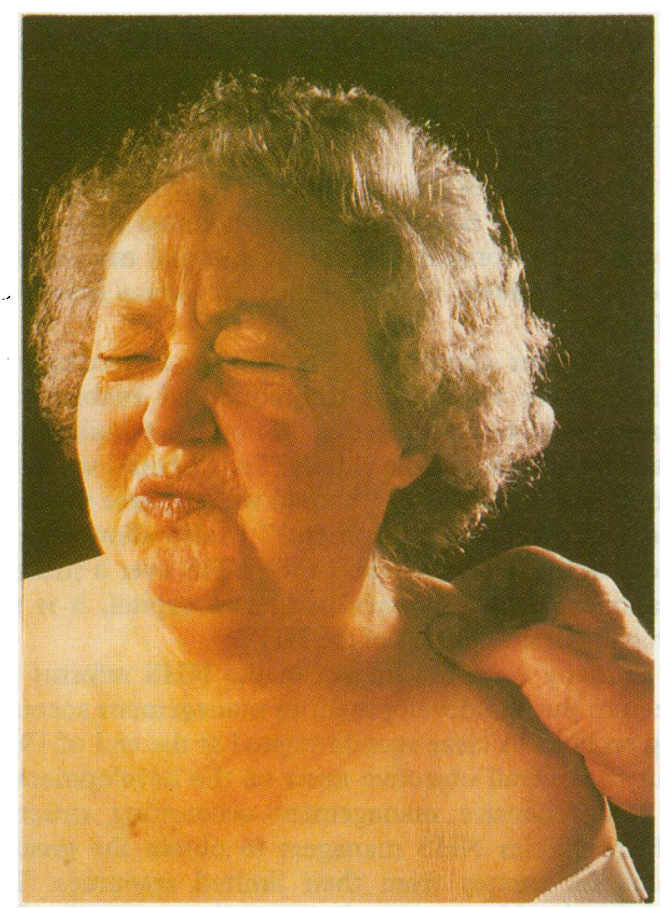

Typical hyperalgesic withdrawal response by patient with fibromyalgia. (Picture reproduced with patient's permission.)

\section{Prevalence of fibromyalgia}

Rheumatology clinics

Internal medicine clinics

Family practice clinics

General medical inpatients

(United Kingdom)

General population

(Swedish city, British general practice)
Fibromyalgia is common in hospital practice. It is rarely reported in children, and most patients are in their $40 \mathrm{~s}$ or $50 \mathrm{~s}$. In all settings there is a strong female preponderance (about $90 \%$ ). It is well reported in the United States, Canada, and Europe, but racial and social predisposition have not been adequately addressed.

Symptoms are variable. Pain and fatiguability are usually prominent and associated with considerable disability and handicap. Although patients can usually dress and wash independently, they cannot cope with a job or ordinary household activities. Pain is predominently axial and diffuse but can affect any region and may at times be felt all over. Characteristically, analgesics, non-steroidal anti-inflammatory drugs, and local physical treatments are ineffective and may even worsen symptoms.

Patients often have a poor sleep pattern with considerable latency and frequent arousal. Typically they awake exhausted and feel more tired in the morning than later in the day. Unexplained headache, urinary frequency, and abdominal symptoms are common and may have been extensively investigated with no cause found. Patients usually score highly on measures of anxiety and depression.

Although the term fibromyalgia syndrome is not ideal, it does not imply causation and describes the commonest symptom. Idiopathic diffuse pain syndrome, generalised rheumatism, and non-restorative sleep disorder are terms that are increasingly preferred by some.

\section{Principal symptoms of fibromyalgia \\ Pain}

Predominantly axial (neck and back), but may be all over

Often aggravated by stress, cold, and activity

Often associated with generalised morning stiffness

Often with subjective swelling of extremities

Paraesthesiae and dysaesthesiae of hands and feet

Fatiguability

Often extreme, occurring after minimal exertion

Non-restorative sleep

Waking unrefreshed

Poor concentration and forgetfulness

Low affect, irritable, and weepy

Headache

Occipital and bifrontal

Diffuse abdominal pain and variable bowel habit

Urinary frequency

Urgency (day and night)

Dysmenorrhoea

\section{Clinical signs}

\section{Principal clinical findings}

- Discordance between symptoms and disability and objective findings

- No objective weakness, synovitis, or neurological abnormality

- Multiple hyperalgesic tender sites (axial and upper and lower limbs)

- Pronounced tenderness to rolling of skin fold (mid-trapezius)

- Cutaneous hyperaemia after palpation of tender sites or rolling of skin fold

- Negative control (non-tender) sites (such as forehead, distal forearm, and lateral fibular head)
Clinical findings are unremarkable, and the principal positive sign is the presence of multiple hyperalgesic tender sites. In normal subjects these tender sites are uncomfortable to firm pressure, but in patients with fibromyalgia similar pressure produces a wince or withdrawal response. The degree of pressure is clearly important; delivery of standard pressure with a spring device (dolorimeter) is ideal, but reasonable palpation suffices for clinical purposes. 


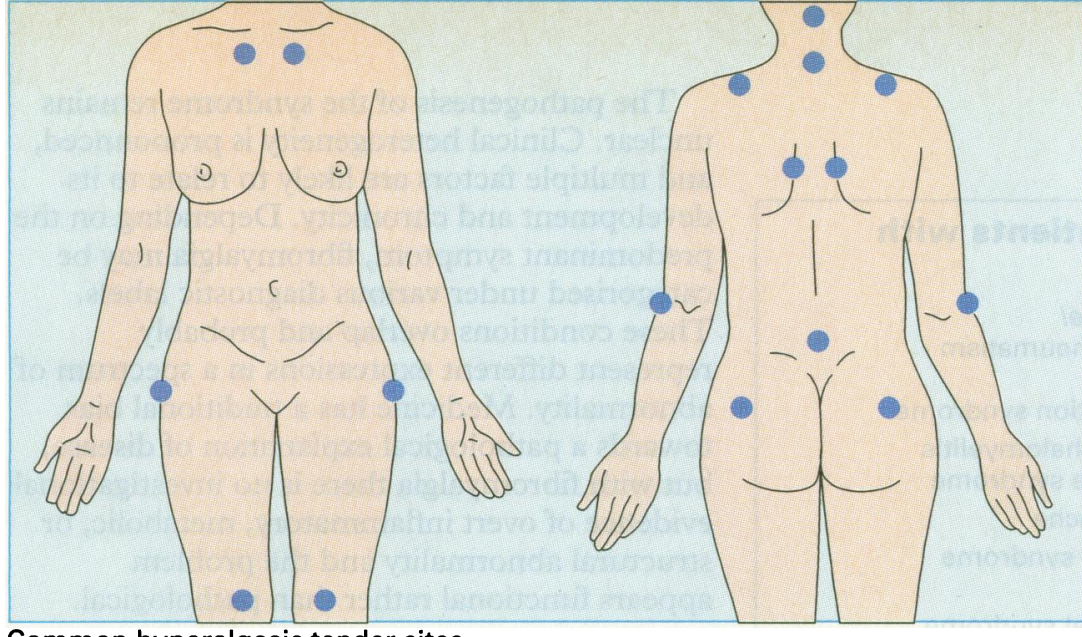

Common hyperalgesic tender sites.
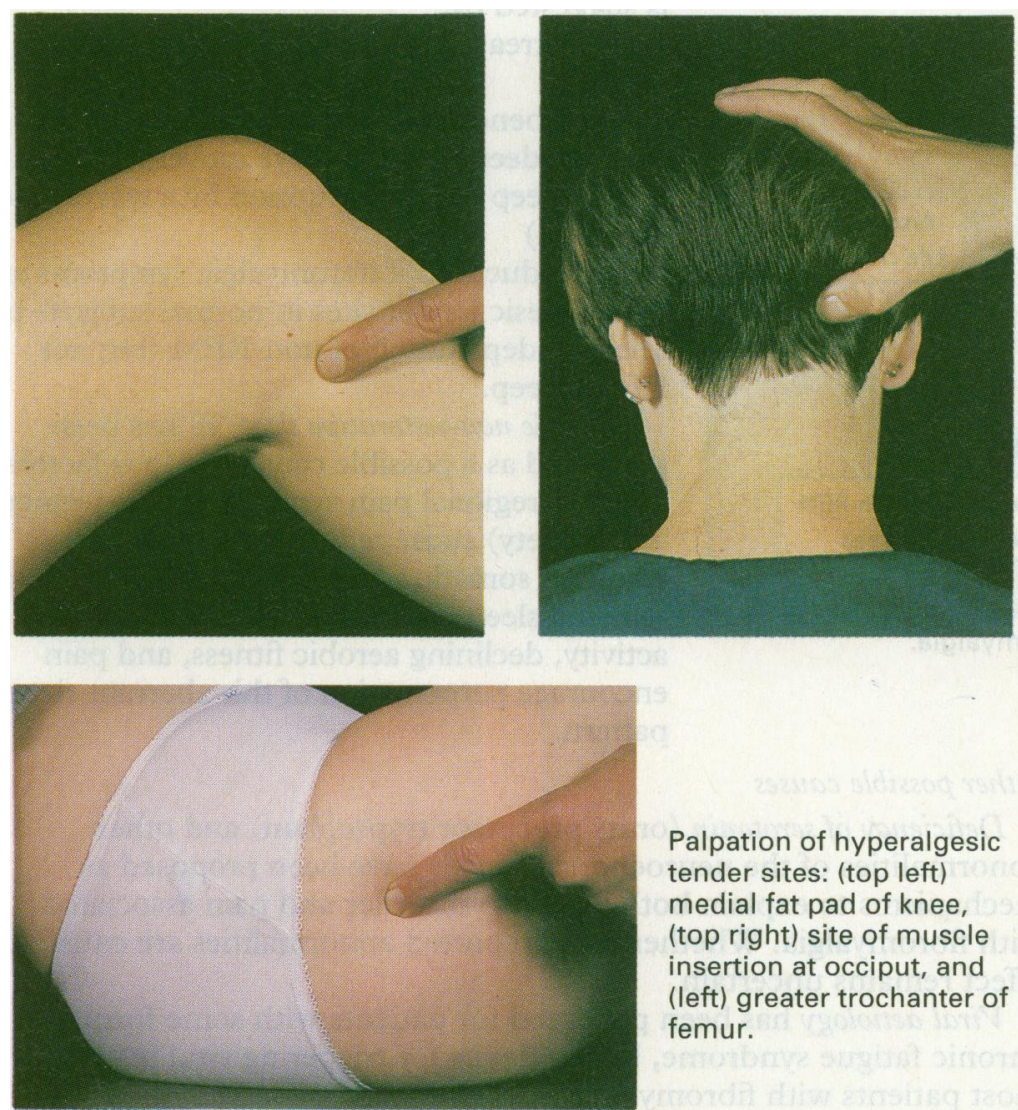

Palpation of hyperalgesic tender sites: (top left) medial fat pad of knee, (top right) site of muscle insertion at occiput, and (left) greater trochanter of femur.

\section{Differential diagnosis}

$\begin{array}{ll}\text { Differential diagnosis and investigations } \\ \text { Differential diagnosis } & \text { Investigations } \\ \text { Hypothyroidism } & \text { Thyroid function tests } \\ \text { Systemic lupus erythematosus } & \begin{array}{l}\text { Full blood count } \\ \text { Erythrocyte sedimentation rate and } \\ \end{array} \\ & \text { blood viscosity } \\ & \text { Antinuclear factor } \\ \text { Inflammatory myopathy } & \text { Creatine kinase concentration } \\ \text { Hyperparathyroidism } & \text { Calcium concentration and alkaline } \\ \text { Osteomalacia } & \text { phosphatase concentration }\end{array}$

\section{Common hyperalgesic tender sites}

- Low cervical spine (C4-C6 interspinous ligaments)

- Low lumbar spine (L4-S1 interspinous ligaments)

- Suboccipital muscle (posterior base of skull)

- Mid-supraspinatus

- Mid-point of upper trapezius

- Pectoralis insertion-maximal lateral to second costochondral junction

- Lateral epicondyle-tennis elbow sites, 1-2 $\mathrm{cm}$ distal to epicondyle

- Gluteus medius-upper, outer quadrant of buttock

- Greater trochanter

- Medial fat pad of knee

Hyperalgesia at one or two sites in the same quadrant often results from periarticular lesions or referred tenderness from an axial structure. In fibromyalgia, however, hyperalgesia is widespread and symmetrical. The number of tender sites required by different diagnostic criteria varies, but eight or more are sufficient for clinical purposes. Importantly, hyperalgesia is absent at sites that are normally non-tender. If a patient claims to be tender all over, fabrication or psychiatric disturbance (psychogenic rheumatism) is more likely. Osteoarthritis and periarticular syndromes are common and may be present as incidental findings or as a trigger for the syndrome.

Other conditions that may present with widespread pain, weakness, or fatigue should be excluded by a limited investigational screen. Further tests may be warranted if a patient's history and examination suggest a predisposing or coexistent condition. Undertaking all investigations together reinforces the patient's confidence in the accuracy of the diagnosis and is preferable to a drawn out sequence of tests. Fibromyalgia may superimpose on pre-existing painful conditions such as osteoarthritis or cancer but usually affects subjects with no other diagnosis (primary fibromyalgia). 


\begin{tabular}{|c|c|}
\hline \multicolumn{2}{|c|}{$\begin{array}{l}\text { Diagnostic terms that often include patients with } \\
\text { fibromyalgia }\end{array}$} \\
\hline $\begin{array}{l}\text { Principal presenting symptom } \\
\text { Locomotor pain }\end{array}$ & $\begin{array}{l}\text { Diagnostic label } \\
\text { Psychogenic rheumatism } \\
\text { Fibrositis } \\
\text { Pain amplification syndrome }\end{array}$ \\
\hline Fatigue & $\begin{array}{l}\text { Myalgic encephalomyelitis } \\
\text { Chronic fatigue syndrome }\end{array}$ \\
\hline Headache & Tension headache \\
\hline $\begin{array}{l}\text { Abdominal pain and bowel } \\
\text { disturbance }\end{array}$ & Irritable bowel syndrome \\
\hline Frequency and nocturia & Female urethral syndrome \\
\hline
\end{tabular}

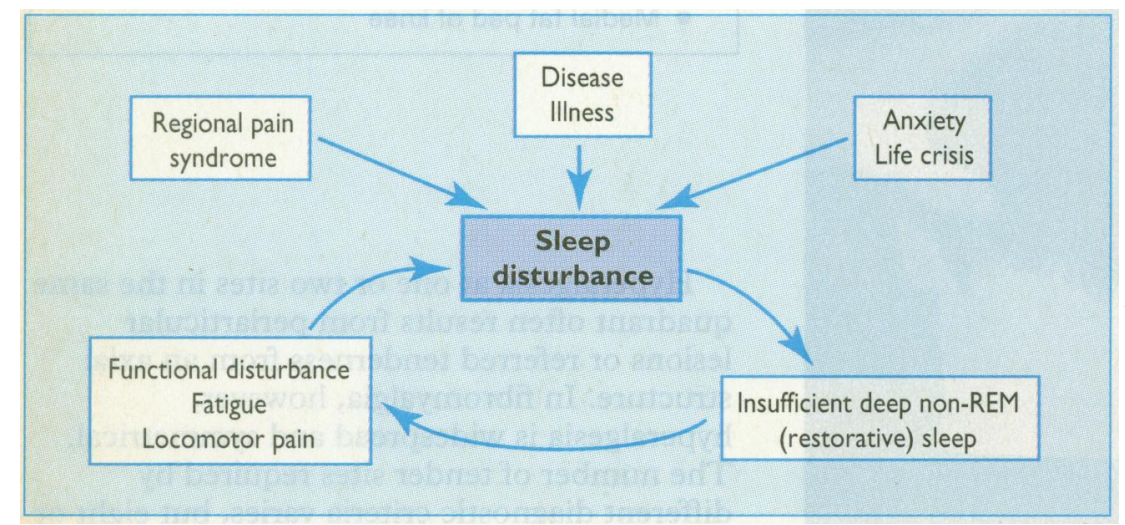

Possible mechanism of induction and perpetuation of fibromyalgia.
The pathogenesis of the syndrome remains unclear. Clinical heterogeneity is pronounced, and multiple factors are likely to relate to its development and chronicity. Depending on the predominant symptom, fibromyalgia may be categorised under various diagnostic labels. These conditions overlap and probably represent different expressions in a spectrum of abnormality. Medicine has a traditional bias towards a pathological explanation of disease, but with fibromyalgia there is no investigational evidence of overt inflammatory, metabolic, or structural abnormality and the problem appears functional rather than pathological.

\section{Sleep disturbance}

A strong association with sleep disturbance is suggested by:

- An increased frequency of non-restorative sleep

- Electroencephalographic evidence of reduced deep non-rapid eye movement (nonREM) sleep with interruption by a waves (a-d intrusion)

- Reproduction of fibromyalgia symptoms and hyperalgesic tender sites in normal subjects by selective deprivation of non-REM (but not REM) sleep.

Chronic non-restorative sleep ` $\mathrm{f} 8^{\text {`h }}$ has been suggested as a possible cause. Various factors (such as regional pain syndrome, bereavement, and anxiety) cause reduced deep sleep, with resultant somatic symptoms and fatigue. Once reduced sleep has been established, reduced activity, declining aerobic fitness, and pain encourage perpetuation of this aberrant sleep pattern.

\section{Other possible causes}

Deficiency of serotonin (or its precursor tryptophan) and other abnormalities of the neuroendocrine axis have been proposed as mechanisms to explain both the sleep disorder and pain associated with fibromyalgia. Whether these reported abnormalities are cause or effect remains uncertain.

Viral aetiology has been proposed for patients with some forms of chronic fatigue syndrome, but evidence for triggering viral infections in most patients with fibromyalgia is lacking.

Affective symptoms are common, though whether they are primary or secondary remains unclear. In fibromyalgia the predominance of locomotor pain, presence of multiple hyperalgesic tender sites, development after selective sleep deprivation, and different response to treatment argue for differentiation from anxiety or depression with somatisation.

\section{Management}

\section{Principal strategies for managing fibromyalgia}

- Educate patient

- Educate patient's family

- Avoid unnecessary investigations and treatments

- Use interventions to correct non-restorative sleep, improve aerobic fitness, and reinforce intrinsic locus of control
There is no specific treatment for this condition, but individual patients may be considerably helped. The single most important pessimistic cause for their devastating symptoms, and they should be reassured that the pain does not reflect cancer, inflammation, or structural damage. An explanation based on poor sleep and reduced fitness is readily understood and helps patients to rationalise their symptoms, disability, and treatments. It is helpful to include family members. Inquiry about life events may reveal problems that merit open discussion and counselling. Patients with sublimated anxiety are more likely to improve if their anxiety is identified and successfully addressed. intervention is a comprehensible explanation. Most patients expect a 


\section{Interventions for managing fibromyalgia}

Low dose amitriptyline

Initially a limited trial of 4-6 weeks

Graded aerobic exercise regimen

Individualised to patient

Set specified targets that increase weekly

Encourage small amounts often

Encourage continuation despite pain

Retrain to avoid operant behaviour

Coping strategies

Meditational yoga

Behavioural therapy
Controlled trials have confirmed the usefulness of low dose amitriptyline or dothiepin (25-75 mg at night) and a graded exercise programme to increase aerobic fitness.

Amitriptyline - The dose used is lower than that for depression. Its efficacy may be due to its normalising effects on the sleep centre or pain gating at the spinal cord level. Interestingly, cyclobenzaprine (a tricyclic muscle relaxant with no antidepressant action) is also effective. If these drugs are ineffective after a trial of four to six weeks, further drug treatment should be avoided. Benzodiazepines and other hypnotics have no place in treatment.

Increasing aerobic exercise is intended to improve sleep and restore fitness. It may initially exacerbate symptoms, but patients should be encouraged to continue despite pain (the opposite advice to that for someone with synovitis or joint damage). An important element is that the locus of control is now within the patient-it is up to them, not doctors or drugs, to improve their situation.

Operant and other illness behaviour is common. This needs to be recognised and eliminated by educating family members.

Coping strategies (such as meditational yoga) may permit patients to better control the extent to which pain and fatigue intervene in their life.

\section{Prognosis}

The prognosis for fibromyalgia is poor. In one British study less than one in 10 patients diagnosed in hospital lost their symptoms over five years.

Nevertheless, suitable advice can help most patients to learn to cope better with their condition and, importantly, to avoid further unnecessary investigations and drug treatments.
Michael Doherty is reader in rheumatology and Adrian City Hospital, Nottingham.

The ABC of Rheumatology is edited by Michael L Snaith, senior lecturer in rheumatology at Nether Edge Hospital, Sheffield.

\title{
The World Health Organisation
}

\section{WHO in Europe: does it have a role?}

\author{
Fiona Godlee
}

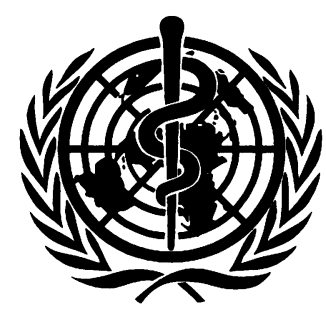

This is the seventh in a series examining the role of the World Health Organisation, its current problems, and its future prospects

British Medical Journal, London WC1H 9JR

Fiona Godlee, assistant editor

Correspondence to:

Department of Ambulatory

Care and Prevention,

Harvard Medical School,

126 Brookline Avenue,

Boston, MA 02215, USA.

BMF 1995;310:389-93
WHO is under pressure from all sides to justify its existence. Donors want to know what they are getting for their money, and health professionals question the relevance of the organisation's work. The pressure to justify itself is perhaps strongest of all in Europe, where most member countries have fully fledged health infrastructures and high overall levels of health. Now there is the additional threat of encroachment into the field of public health by the European Union. The disintegration of the Soviet bloc has given WHO's regional office in Europe a new sense of purpose and led to a major shift in resources towards the countries of central and eastern Europe. But WHO's critics are calling for a different shift in the way its European office works: from its current concentration on broad based policy issues to the nitty-gritty of health care management and delivery.

Article 129 of the Maastricht treaty of 1993 gives the European Union "competence" in the field of public health. With the union already funding medical research and taking an interest in disease prevention and data collection, article 129 raises questions about the future of WHO. What, people ask, does WHO do in Europe? Does it need the regional office in Copenhagen? Could there not be a small office within the Geneva headquarters responsible for collecting data, setting normative standards, and producing reports? A recent critical analysis of WHO's budgetary priorities points out that the European office has been allocated $\$ 56.6 \mathrm{~m}$ for $1994-5$, compared with $\$ 36.6 \mathrm{~m}$ allocated to programmes dealing with tropical disease. ${ }^{1}$ The authors argue that European countries are competent to look after their own people and are already spending an average of $\$ 642$ per person per year on health compared with about $\$ 9$ in low income countries. Closing the European office would, they conclude, allow WHO to increase the country budgets in Africa by two thirds.

\section{A new sense of purpose}

Five years ago WHO might have found itself hard pressed to defend its European operation from these offensives. But conflict and economic decline in central and eastern Europe have given the European office a new sense of purpose. Before 1989 the office was concerned mainly with promulgating Health for All and promoting primary health care in the region's 32 member states. Since the disintegration of the Soviet bloc the region's membership has grown to 50 . Twelve newly independent states and three Baltic states have joined the organisation, as have the warring states of the former Yugoslavia.

The region's new members have enormous health problems. In the newly independent and Baltic states, health care continues to rely on an inefficient, overstaffed service, and the collapse of the central command economy has brought severe shortages of drugs and medical equipment. The health of women and children is a major concern. In the absence of adequate contraception, abortion rates in 1990 were running at more than one for every live birth in many countries of the former USSR, compared with about one in five in western Europe. Poor socioeconomic conditions and the collapse of state run immunisation programmes have led to the re-emergence of diseases like diphtheria, 